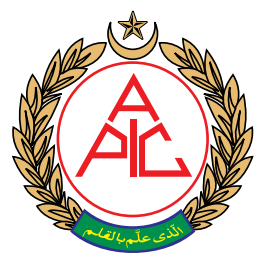

\title{
Comparative study of intrathecal nalbuphine versus clonidine as adjuvants to $0.5 \%$ isobaric levobupivacaine for elective infra umbilical surgeries
}

\author{
Shalini A., Kokila N., Manjunatha H, G., Supriya L.
}

\author{
Shalini A, Assistant professor, \\ Department of Anesthesiology, \\ Mysore Medical College \& \\ Research Institute, Mysuru \\ 570001, Karnataka, (India) \\ [shalinianand20@gmail.com] \\ Kokila N, Assistant professor, \\ Department of Anesthesiology, \\ Mysore Medical College \& \\ Research Institute, Mysuru \\ 570001, Karnataka, (India) \\ [kokila222008@gmail.com] \\ Manjunatha HG, Professor \\ and Head, Department of \\ Anesthesiology, Mysore Medical \\ College \& Research Institute, \\ Mysuru 570001, Karnataka, \\ (India) [drhgmanjunathanes@ \\ gmail.com] \\ Supriya L, Postgraduate, \\ Department of Anesthesiology, \\ Mysore Medical College \& \\ Research Institute, Mysuru \\ 570001, Karnataka, (India) \\ [supriya.goals02@gmail.com] \\ Correspondence: Dr. Kokila. N, \\ \# 312, 9th main, 1st B cross, \\ 1st stage, Brindavan Extension, \\ Mysuru, Karnataka-570020, \\ (India) \\ Received: 21 August 2019, \\ Reviewed: 13 September, 22 \\ November 2019, \\ Accepted: 26 November 2019
}

\begin{abstract}
Background and objectives: Various intrathecal adjuvants have been clinically tried for the prolongation of intraoperative and postoperative analgesia. This study aims at evaluating the effects of intrathecal nalbuphine and clonidine as adjuvants to isobaric levobupivacaine in subarachnoid block.
\end{abstract}

Methodology: 60 patients scheduled for elective infra umbilical surgeries were allocated into two groups of thirty each to receive $15 \mathrm{mg}$ of $0.5 \%$ isobaric Levobupivacaine with either $1 \mathrm{mg}$ nalbuphine (Group LN) or $30 \mu \mathrm{g}$ clonidine (Group LC) intrathecally. Characteristics of spinal anesthesia in terms of sensory analgesia and motor blockade were noted. Hemodynamic parameters and adverse effects if any were recorded. Data obtained was compiled and statistically analysed with appropriate tests.

Results: Onset of sensory and motor blocks was faster in group LN (2.43 \pm 0.93 and 2.2 $\pm 0.9 \mathrm{~min})$ compared to group LC ( $3.26 \pm 1.04$ and $3.13 \pm 1.0 \mathrm{~min})$. However, time to two segment regression $(186.8 \pm 24.5$ vs $146.5 \pm 21.4)$, total duration of effective analgesia (384.1 \pm 56.6 vs $292.1 \pm 40.9$ ) and total duration of motor block (345.3 \pm 41.7 vs 235.6 $\pm 29.5 \mathrm{~min}$ ) were significantly prolonged in group LC than in group LN. There was no significant difference in hemodynamic changes and adverse effects between the groups.

Conclusion: The addition of $30 \mu \mathrm{g}$ clonidine to intrathecal $0.5 \%$ isobaric levobupivacaine as adjuvant, is associated with prolonged sensory and motor blockade with better perioperative analgesia compared to $1 \mathrm{mg}$ nalbuphine.

Key words: Infra umbilical surgeries; Intrathecal; Nalbuphine; Clonidine; Isobaric levobupivacaine.

Citation: Shalini A, Kokila N, Manjunatha HG, Supriya L. Comparative study of intrathecal nalbuphine versus clonidine as adjuvants to $0.5 \%$ isobaric levobupivacaine for elective infra umbilical surgeries. Anaesth pain \& intensive care 2019;23(4):370-

376. DOI: https://doi.org/10.35975/apic.v23i4.1169

\section{INTRODUCTION}

Spinal anesthesia though introduced more than 100 years back is still the standard anesthetic technique practiced for infra umbilical surgeries but the main drawback is its limited duration of action and does not provide prolonged postoperative analgesia if only local anesthetic is administered. ${ }^{1}$ Alleviation of pain is of principal importance for the anesthesiologist in perioperative period, as it helps in smoother postoperative course and earlier discharge from hospital. $^{2}$

Intrathecal adjuvants increase the speed of onset (reduce latency), improve the quality and prolong the duration of neural blockade. There are myriad choices of neuraxial adjuvants like opioids (morphine, fentanyl, buprenorphine, nalbuphine), N-methyld-aspartate (NMDA) antagonists (ketamine), 
alpha 2 adrenoceptor agonists (clonidine and dexmedetomidine), vasoconstrictors (adrenaline), GABA receptor agonists (midazolam), cholinergic agonists (neostigmine) and sodium bicarbonate but no drug inhibits nociception without its associated adverse effects. $^{3}$

Intrathecal opioids are synergistic with local anesthetics, thereby intensifying sensory block without affecting the sympathetic blockade. ${ }^{2}$ However, opioids may produce side effects like pruritus, nausea, vomiting, respiratory depression, sedation, urinary retention and shivering. ${ }^{4}$ Most of these side effects are mainly due to their action on mu opioid receptor. Nalbuphine is a synthetic, mixed agonist-antagonist opioid analgesic with agonistic action at kappa receptor and antagonism at mu receptor. The main advantage is its increased margin of safety due to ceiling effect on respiratory depression and sedation. ${ }^{5}$ Despite these good qualities of nalbuphine, its use is not widespread for regional anesthesia.

By using non-opioid drugs as an alternative to opioids the side effects of opioids can be avoided. Clonidine is a selective partial alpha 2 adrenergic agonist, and its intrathecal administration prolongs sensory as well as motor block when used as an adjuvant to local anesthetic. Analgesic action is due to its binding on alpha 2 receptors located in brainstem nuclei and spinal substantia gelatinosa. Clonidine also has antiemetic, anxiolytic, antishivering, sedative properties without respiratory depression. . $7,7,8,9,10^{2}$

Levobupivacaine, a levo-isomer of bupivacaine which is available as an isobaric preparation produces sensory and motor blockade similar to bupivacaine but has less cardiotoxic potential and lesser motor blockade leading to early mobilization of the patient. Its decreased toxicity is attributed to its less affinity and inhibitory effect on cardiac sodium channels and faster protein binding rate. . $^{7,10,11}$

There are various studies conducted to compare the efficacy of intrathecal nalbuphine and clonidine at various doses with hyperbaric bupivacaine. ${ }^{1,5,12}$ The present study was designed to evaluate the sensory and motor block characteristics, hemodynamic changes and any adverse effects of nalbuphine and clonidine when used as adjuvants to $0.5 \%$ isobaric levobupivacaine in patients undergoing elective infra umbilical surgeries under subarachnoid block.

\section{METHODOLOGY}

After institutional ethical committee approval, a prospective, double blind, randomized clinical study was conducted on 60 patients who gave a valid informed written consent and belonged to American Society of Anesthesiologists (ASA) class I and II, in the age group of $18-60 \mathrm{y}$, with a height $150-170 \mathrm{~cm}$, undergoing elective infra umbilical surgeries under subarachnoid block at our tertiary care hospital.

Patients with systemic diseases like diabetes mellitus, hypertension, cardiovascular, respiratory, hepatic, renal or neurologic disorders, and posted for emergency surgeries were excluded from the study. Unwilling patients, patients with history of known hypersensitivity to study drugs, or any contraindication to subarachnoid block, were also excluded from the study.

Sixty patients were randomly allocated into two groups of thirty each by shuffled sealed opaque envelope method. A thorough pre-anesthetic checkup was carried out for each patient with relevant laboratory and radiological investigations. All patients were visited a day prior to the surgery and explained in detail about the anesthetic technique and visual analogue scale (VAS). Tablet ranitidine $150 \mathrm{mg}$ and tablet alprazolam $0.5 \mathrm{mg}$ orally was given at night as pre-medication and patients were kept nil orally from 12 midnight. On the day of surgery, after securing an intravenous access with $18 \mathrm{G}$ cannula patients were preloaded with Ringer lactate solution $10 \mathrm{ml} / \mathrm{kg}$ before the initiation of spinal anesthesia.

Ampoules containing drugs $0.5 \%$ isobaric levobupivacaine (LEVO-ANAWIN $0.5 \%$ by Neon Laboratories limited), inj. clonidine hydrochloride (CLONEON $150 \mu \mathrm{g} / \mathrm{ml}$ by Neon laboratories limited) and inj nalbuphine hydrochloride (NACPHIN 10 $\mathrm{mg} / \mathrm{ml}$ by Neon laboratories limited) were used for the study. The study drugs were loaded in a $5 \mathrm{ml}$ syringe by an anesthesiologist who was not a part of the study, just before intrathecal injection.

Intraoperative monitoring was done with baseline recording of heart rate (HR), oxygen saturation (SPO2), non-invasive blood pressure (NIBP) and electrocardiography (ECG) using automated multiparameter monitor. Under aseptic precaution, subarachnoid block was performed at L3-L4 interspace using $25 \mathrm{G}$ Quincke's spinal needle with patient in lateral position by using midline approach after local infiltration of skin with lignocaine $2 \%$. All the subarachnoid blocks were performed and monitored by the same anesthesiologist, who was also the observer of the study. Thus, both the observer and the subjects were blinded to the study drugs achieving double blinding. The patients received either of the drug solution below

Group LN - $3 \mathrm{ml}$ of $0.5 \%$ isobaric levobupivacaine + $0.1 \mathrm{ml}$ of nalbuphine $(1 \mathrm{mg})+0.1 \mathrm{ml}$ normal saline to make a total volume of $3.2 \mathrm{ml}$ or

Group LC $-3 \mathrm{ml}$ of $0.5 \%$ isobaric levobupivacaine + $0.2 \mathrm{ml}$ of clonidine $(30 \mu \mathrm{g})$ to a total volume of $3.2 \mathrm{ml}$

Time of intrathecal injection was noted. Sensory testing was assessed by loss of pinprick sensation to 
a blunt 27G hypodermic needle and degree of motor block assessed by modified Bromage scale.

Onset of sensory block was considered as the time taken from intrathecal injection of drug to loss of sensation to pinprick at T10 dermatome. Maximum level of sensory block attained, time taken for maximum dermatomal level, two segment sensory regression time, total duration of effective analgesia (the time from intrathecal injection of drug to the first request of analgesia with VAS $>3$ ) were noted. The time needed for the onset of motor block (Bromage 1), time taken for maximum motor block and total duration of motor block (time taken for complete motor recovery to Bromage 0 ) were also noted.

Hemodynamic parameters like heart rate (HR), systolic blood pressure (SBP), diastolic blood pressure (DBP), mean arterial blood pressure (MAP) and respiratory rate were monitored every $2 \mathrm{~min}$ for the first $10 \mathrm{~min}$, every $5 \mathrm{~min}$ for the next $30 \mathrm{~min}$ and then every $15 \mathrm{~min}$ till the completion of surgery.

Mephentermine $6 \mathrm{mg}$ was given to treat arterial hypotension (fall in SBP $>20 \%$ from basal value or $<90 \mathrm{mmHg}$ ). Atropine was used if $\mathrm{HR}$ went below $55 \mathrm{bpm}$.

Incidence of side effects like nausea, vomiting, respiratory depression (respiratory rate $<10 / \mathrm{min}$ and $\mathrm{SpO}_{2}<90 \%$ ), shivering, pruritus etc. were monitored throughout the procedure and postoperatively. Sedation was assessed by Ramsay sedation scoring.

After the surgery patients were shifted to post anesthesia care and recovery unit and monitored until complete recovery from spinal anesthesia. Postoperative pain was assessed by VAS, where patients were asked to mark on the scale the degree of pain experienced every half an hour. When they complained of pain with VAS $>3$, inj. diclofenac 75 mg intramuscular was given and the study ended.

Statistical analysis:

Sample size calculation was based on previous studies. An estimated 26 patients per group were

Table 1: Showing demographic characteristics (Mean \pm SD)

\begin{tabular}{l|c|c|c}
$\begin{array}{c}\text { Demographic } \\
\text { criteria }\end{array}$ & Group LN & Group LC & p value \\
Age (y) & $41.9 \pm 12.80$ & $40.5 \pm 11.11$ & $0.736(\mathrm{NS})$ \\
\hline Sex (male /female) & $23 / 7$ & $22 / 8$ & $0.762(\mathrm{NS})$ \\
\hline Height (cm) & $164.1 \pm 5.76$ & $162.2 \pm 6.95$ & $0.128(\mathrm{NS})$ \\
\hline Weight $(\mathrm{kg})$ & $58.12 \pm 5.69$ & $56.90 \pm 4.85$ & $0.177(\mathrm{NS})$ \\
\hline ASA 1/2 & $14 / 16$ & $18 / 12$ & $0.301(\mathrm{NS})$ \\
\hline $\begin{array}{c}\text { Duration of } \\
\text { surgery (min) }\end{array}$ & $59.3 \pm 18.69$ & $60.8 \pm 15.81$ & $0.738(\mathrm{NS})$ \\
\hline NS- not significant $(p>0.05)$ &
\end{tabular}

necessary in order to detect at least clinically significant difference of $30 \mathrm{~min}$ in mean duration of analgesia between the groups for achieving type 1 error of 0.05 with $80 \%$ power and $95 \%$ confidence interval for group comparison. To compensate for the dropouts from the study and to make sure that the sample size is adequate, we selected 60 subjects. Continuous variables were summarized in the form of mean \pm standard deviation (SD), median (range) and categorical variables as percentages. The results were analyzed statistically using Student's t-test (for continuous variables) and Chi-square test (for categorical variables). All variables are presented in the form of tables and graphs

Data were entered in a spreadsheet and then exported to data editor of Statistical Package for Social Sciences (SPSS; Windows version 22.0) for analysis. $\mathrm{p}<0.05$ was considered to be significant, and $<0.01$ as highly significant.

\section{RESULTS}

The two groups of patients enrolled in the study did not differ significantly with respect to age, sex, body weight, height, ASA status and duration of surgery as shown in Table 1.

The salient features regarding sensory and motor block characteristics in both the groups are tabulated in Tables 2 and 3 respectively.

In our study time to achieve T10 dermatomal level of analgesia was faster in group $\mathrm{LN}$ when compared to group LC which was statistically highly significant $(\mathrm{p}<0.01)$. The maximum sensory level achieved in both the groups were comparable and statistically not significant $(\mathrm{p}=0.293)$. The time taken to achieve this maximum sensory level was also statistically insignificant with a $\mathrm{p}$ value of 0.226 . The time taken for sensory level regression by two dermatomes in group LC was significantly longer than in group LN $(\mathrm{p}<0.01)$. The total duration of effective analgesia was significantly longer in group LC when compared to group $\mathrm{LN}(\mathrm{p}<0.01)$.

In our study onset of motor block was significantly faster in group LN. Complete motor blockade of Bromage 3 was achieved in all 30 patients in group $\mathrm{LC}$ and 28 patients in group $\mathrm{LN}(\mathrm{p}=0.15)$. The difference in time taken to achieve Bromage 3 was not significant $(\mathrm{p}>0.05)$. The total duration of motor block was significantly prolonged $(\mathrm{p}<0.01)$ in group LC.

Regarding hemodynamic changes there were no significant alterations in the measured parameters between the two groups $(\mathrm{p}>0.05)$ at various time intervals. Variations in mean HR and MAP are shown in Figures 1 and 2 respectively. 
Ramsay sedation score used for sedation assessment was $<$ or $=2$ and was comparable in both the groups ( $p$ $>0.05$ ). Incidence of adverse effects observed in both the groups are tabulated in Table 4 below.

\section{DISCUSSION}

Spinal anesthesia is the most commonly used technique for infra umbilical surgeries because it is easy, reliable, provides good analgesia and muscle relaxation, cost effective and analgesia extends into the postoperative period too. ${ }^{13}$ To improve the subarachnoid block characteristics adjuvants like opioids and alpha 2 agonists are often being used with intrathecal local anesthetics.

The rationale for combining opioids with local anesthetics intrathecally is that two different types of drugs eliminate pain by acting at two different sites in spinal cord, local anesthetics at the nerve axonal level (by blocking voltage gated sodium channels) and opioids at the receptor level (substantia gelatinosa to modulate the function of afferent pain carrying nerve fibers). Some of this intrathecal opioid gets absorbed into the systemic circulation and acts on the opioid receptors at brain. ${ }^{13}$ Degree of this absorption depends upon the lipophilicity of the drug. Nalbuphine a synthetic opioid has agonistic action at kappa receptor and antagonistic action at $\mathrm{mu}$ receptor. It stimulates the
Table 2: Sensory block characteristics (Mean \pm SD)

\begin{tabular}{l|l|l|l}
\multicolumn{1}{c|}{ Sensory block data } & \multicolumn{1}{c|}{ Group LN } & \multicolumn{1}{c|}{ Group LC } & \multicolumn{1}{c}{ p value } \\
\hline Time of sensory block to T10 (min) & $2.43 \pm 0.93$ & $3.26 \pm 1.04$ & $0.002(\mathrm{HS})$ \\
\hline Maximal dermatomal level achieved T4/T6/T8/T10 $(\mathrm{n})$ & $1 / 8 / 14 / 7$ & $0 / 7 / 20 / 3$ & $0.293(\mathrm{NS})$ \\
\hline Time to achieve max dermatomal level $(\mathrm{min})$ & $6.0 \pm 2.49$ & $6.7 \pm 1.89$ & $0.226(\mathrm{NS})$ \\
\hline Time to two segment sensory level regression $(\mathrm{min})$ & $146.5 \pm 21.4$ & $186.8 \pm 24.5$ & $0.000(\mathrm{HS})$ \\
\hline Total duration of effective analgesia (min) & $292.1 \pm 40.9$ & $384.1 \pm 56.6$ & $0.000(\mathrm{HS})$ \\
\hline
\end{tabular}

HS-Highly significant, $p<0.01$; NS- not significant, $p>0.05$

Table 3: Characteristics of motor blockade (Mean \pm SD)

\begin{tabular}{l|l|l|l}
\multicolumn{1}{c|}{ Motor blockade data } & \multicolumn{1}{c|}{ Group LN } & \multicolumn{1}{c|}{ Group LC } & \multicolumn{1}{c|}{ p value } \\
\hline Time to onset $(\mathrm{min})$ & $2.2 \pm 0.9$ & $3.13 \pm 1.0$ & 0.001 (HS) \\
\hline Time to achieve complete motor block $(\mathrm{min})$ & $5.40 \pm 2.42$ & $5.80 \pm 2.48$ & $0.529(\mathrm{NS})$ \\
\hline Total duration of motor block $(\mathrm{min})$ & $235.6 \pm 29.5$ & $345.3 \pm 41.7$ & $0.000(\mathrm{HS})$ \\
\hline
\end{tabular}

HS-Highly significant, $p<0.01 ;$ NS- not significant, $p>0.05$

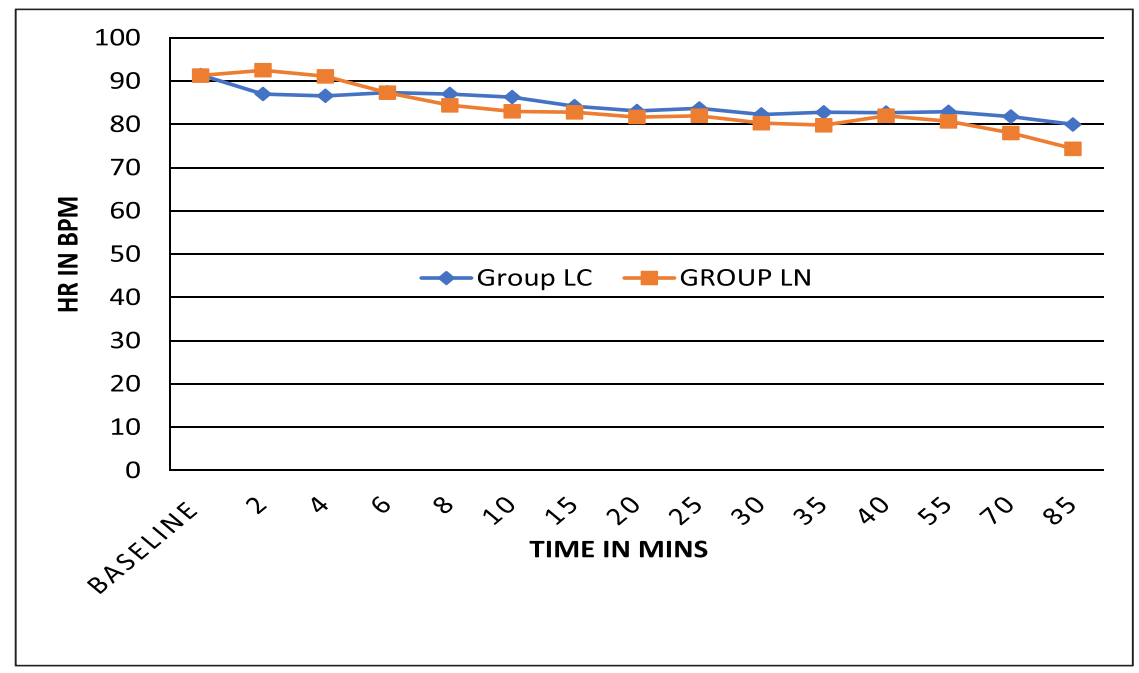

Figure 1: Showing changes in mean heart rate (in bpm) at various time intervals

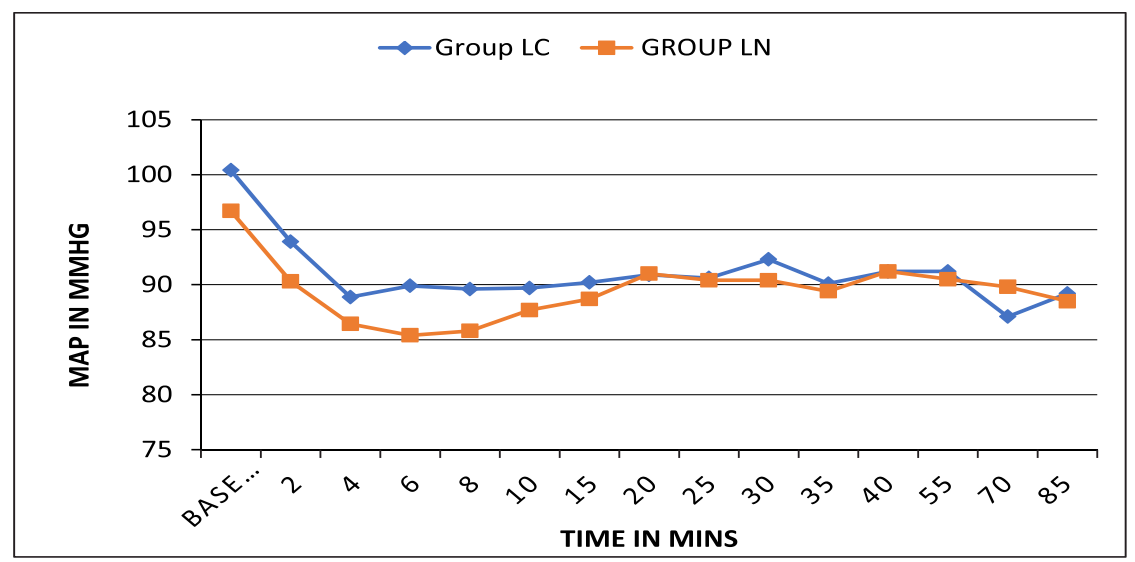

Figure 2: Showing mean arterial blood pressure changes (in $\mathbf{m m ~ o f ~} \mathbf{H g}$ ) at various time intervals 
Table 4: Comparative incidence of adverse effects

\begin{tabular}{l|c|c|c}
\multicolumn{1}{c|}{ Adverse effect } & $\begin{array}{c}\text { Group LN } \\
\mathbf{n}(\%)\end{array}$ & $\begin{array}{c}\text { Group LC } \\
\mathbf{n}(\%)\end{array}$ & p value \\
\hline Hypotension & $3(10 \%)$ & $4(13.3 \%)$ & $0.688(\mathrm{NS})$ \\
\hline Bradycardia & 0 & $1(3.3 \%)$ & $0.313(\mathrm{NS})$ \\
\hline Shivering & 0 & $1(3.3 \%)$ & $0.313(\mathrm{NS})$ \\
\hline Nausea and vomiting & $2(6.6 \%) \mathrm{I}$ & $2(6.6 \%)$ & $1(\mathrm{NS})$ \\
\hline NS- not significant $(p>0.05)$ &
\end{tabular}

NS- not significant $(p>0.05)$

kappa receptor and produces analgesia without the undesirable side effects of $\mathrm{mu}$ receptor agonism. It inhibits the release of substance $P$, which is a neurotransmitter that mediates pain. In addition, it acts as a post synaptic inhibitor of interneuron and ascending nociceptive spinothalamic tract. ${ }^{12,13}$ Since it is highly lipid soluble it diffuses into systemic circulation fast unlike hydrophilic opioid like morphine, thereby producing short duration of action. It is safe to use intrathecally unlike morphine which can cause delayed respiratory depression due to rostral spread in CSF. ${ }^{13}$

Clonidine is the most commonly used alpha 2 agonist in neuraxial anesthesia with well- established record of safety and efficacy. Clonidine is a partial alpha2 agonist with $\alpha 1: \alpha 2$ receptor affinity at a ratio of 200:1. ${ }^{12}$ It acts synergistically with local anesthetics by opening potassium channels. Analgesic effect of clonidine is attributed to its blocking of $\mathrm{C}$ and $\mathrm{A}$ delta fibers. ${ }^{14}$ Spinal clonidine binds to postsynaptic $\alpha 2$ receptors in substantia gelatinosa of spinal cord. ${ }^{9}$ It also augments acetylcholine release due to its cholinergic activity, which increases the amount of acetylcholine available for modulating pain at the level of substantia gelatinosa. ${ }^{12}$

The appropriate dose of intrathecal nalbuphine has been debated. It has been used as an additive with bupivacaine intrathecally in several clinical settings in doses ranging from $0.2 \mathrm{mg}$ - $2.4 \mathrm{mg}$. ${ }^{3,15,16,17,18,19}$ Rawal et $\mathrm{al}^{20}$ showed in a sheep model that intrathecal nalbuphine is not neurotoxic even in large doses 15$24 \mathrm{mg}$ and is not associated with histopathological changes in spinal cord. From previous studies we found that increasing the dose to more than $2 \mathrm{mg}$ showed no benefit, but increased the incidence of side effects. ${ }^{3,18,19}$ This is because nalbuphine exerts ceiling effect, increase in the dose increases analgesic effect upto a certain point beyond which there is no further increase in analgesia. So based on these studies we have chosen $1 \mathrm{mg}$ nalbuphine for our study like various researchers. ${ }^{11,21,22,23}$

The optimal dose of clonidine for intrathecal use remains unknown, ranging from $15 \mu \mathrm{g}$ to $150 \mu \mathrm{g}$ with variable results. Walker et al. ${ }^{25}$ have shown the absence of neurotoxicity with intrathecal clonidine. Various authors have studied different doses of clonidine intrathecally and concluded that better prolongation of analgesia and motor block with minimal hemodynamic changes and sedation is seen when $30 \mu$ g clonidine was used. ${ }^{2,5,10,12,26,27,28,29}$ Based on these studies we chose $30 \mu \mathrm{g}$ clonidine for our study.

In our study, the onset of sensory block and motor block was faster in nalbuphine group compared to clonidine group. However the maximum sensory level attained and the time taken to achieve this peak sensory level were comparable and statistically not significant. Our results correlate to other studies, ${ }^{1,5,11}$ The time taken to sensory level regression by two dermatomes and the total duration of effective analgesia were significantly longer in clonidine group compared to nalbuphine group $(\mathrm{p}<0.01)$ as shown by other studies. ${ }^{5,12}$ Our findings also correlate with the findings by Das $\mathrm{T}$ et $\mathrm{al}^{11}$ who studied levobupivacaine with various doses of nalbuphine $(0.5 \mathrm{mg}, 0.75 \mathrm{mg}$ and $1 \mathrm{mg}$ ) in patients receiving spinal anesthesia.

The time taken to achieve maximum motor blockade (Bromage 3) was comparable between the two groups. The duration of motor block was significantly prolonged in clonidine group when compared to nalbuphine group, as shown by various researchers. ${ }^{5,12,16,24}$

Hemodynamic parameters revealed no statistically significant difference. Incidence of adverse effects were comparable between the groups. There was no incidence of pruritus, respiratory depression and desaturation in both the groups. Low dose clonidine is not associated with hemodynamic instability and opioid related side effects were not observed since nalbuphine is a mu receptor antagonist. Our findings correlate well with previous studies. ${ }^{5,12,13}$

\section{CONCLUSION}

On the basis of the results of our study, we conclude that addition of $30 \mu \mathrm{g}$ of clonidine to intrathecal $0.5 \%$ isobaric levobupivacaine as adjuvant is preferable to 1 $\mathrm{mg}$ of nalbuphine, as it provides comparatively more prolonged sensory and motor blockade with better perioperative analgesia.

Conflict of interest: None declared by the authors

Authors' contribution:

SA: Concept and design, conduct of study, review of articles, preparation of manuscript

KN: Conduct of study, preparation of manuscript, review of article MHG: Manuscript editing

SL: Conduct of study, data collection 
original article

\section{REFERENCES}

1. Kumar R, Sharan R, Bhanavath $G$, Jarewal V, Neki NS. Comparison of intrathecal nalbuphine and clonidine as adjuvants to hyperbaric bupivacaine in infraumbilical surgeries. Int J Curr Res Biol Med. 2018;3(2):1-8 [Free Full $\underline{\text { Text] }}$

2. Bindra TK, Kumar P, Jindal G. Postoperative analgesia with intrathecal nalbuphine versus intrathecal fentanyl in caesarean section: A double blind randomized comparative study. Anesth Essays Res 2018;12:561-5 [PubMed] [Free Full Text]

3. Ahmed $F$, Narula $H$, Khandelwal $M$, Dutta D. A comparative study of three different doses of nalbuphine as an adjuvant to intrathecal bupivacaine for postoperative analgesia in abdominal hysterectomy. Indian J Pain 2016;30:23-8.

4. Gwirtz KH, Young JV, Byers RS, Alley C, Levin K, Walker SG, et al. The safety and I efficacy of intrathecal opioid analgesia for acute postoperative pain: Seven years' experience with 5969 surgical patients at Indiana University Hospital. Anesth Analg 1999;88:59960

5. Bansal M, Agarwal S, Gupta K, Gupta PK, Agarwal S, Pandey MN. Clinical efficacy of clonidine versus nalbuphine as intrathecal adjuvants to $0.5 \%$ hyperbaric bupivacaine for subarachnoid block during gynaecological procedures: A double blind study. Int J Res Med Sci 2017;5:2540-5I [Free Full Text] DOl: 10.18203/2320-6012.ijrms20172444

6. Sarma J, Narayana PS, Ganapathi P, Shivakumar MC. A comparative study of intrathecal clonidine and dexmedetomidine on characteristics of bupivacaine spinal block for lower limb surgeries. Anesth Essays Res 2015 May-Aug;9(2):195-207. [PubMed] [Free Full Text]

7. Bhavani V, Raajesh IJ. Comparison of intrathecal isobaric levobupivacaine, levobupivacaine-clonidine, with hyperbaric bupivacaine as a control for quality of anaesthesia intraoperative hemodynamics and duration of post-operative pain relief in patients undergoing vaginal hysterectomy. Indian J Clin Anaesth, 2016;3(2):148154. [Free Full Text] DOl: 10.5958/2394-4994.2016.00031.7

8. Kulkarni J, Lodha V, Patil T, Misal U. Comparison of levobupivacaine and clonidine with bupivacaine and clonidine in spinal anaesthesia for lower segment caesarean section. IOSR J Dent Med Sci. 2016;15(8):9297. [Free Full Text] DOI: 10.9790/08531508019297

9. Sudeep, Reddy NG. Comparison of levobupivacaine and clonidine with plain levobupivacaine in spinal anaesthesia in lower limb surgeries. MedPulse Inter J Anesth. 2017;3(1):26-29. [Free Full Text]

10. Kulkarni J, Lodha V, Patil T, Misal U. Comparison of levobupivacaine and clonidine with bupivacaine and clonidine in spinal anaesthesia for lower segment caesarean section. IOSR J Dent Med Sci. 2016;15(8):9297

11. Das T, Ray $H$, Baliarsingh P. A comparative study of efficacy of intrathecal nalbuphine in differentdoses as an adjuvant to levobupivacaine in subarachnoid block. Sch J App Med Sci Jun 2017;5(6E):2388-2392.

12. Chetty DK, Ahmed F, Chatterjee $\underline{R}$, Rathore M. Comparison of intrathecal nalbuphine hydrochloride and clonidine hydrochloride as an adjuvant to hyperbaric bupivacaine in abdominal hysterectomy. Anesth Essays Res. 2018;12(2):402-406. [PubMed] [Free Full Text]

13. Koppal R, Naik D, Mathpati V, Hulkund S. A comparative study of intrathecal $0.5 \%$ isobaric levobupivacaine with fentanyl and $0.5 \%$ isobaric levobupivacaine with nalbuphine in infraumbilical surgeries: A randomized double blind clinical trial. Indian J Clin Anaesth 2019;6(2)203-8

14. Wei ZY, Karim F, Roerig SC. Spinal morphine/clonidine antinociceptive synergism: involvement of $\mathrm{G}$ proteins and N-type voltage-dependent calcium channels. J Pharmacol Exp Ther 1996 Sep;278(3):1392-407 [PubMed]

15. Tiwari AK, Tomar GS, Agrawal J. Intrathecal bupivacaine in comparison with a combination of nalbuphine and bupivacaine for subarachnoid block: A randomized prospective doubleblind clinical study. Am J Ther 2013 Nov-Dec;20(6):592-5. [PubMed] doi: 10.1097/MJT.0b013e31822048db.

16. Mukherjee A, Pal A, Agrawal J, Mehrotra A, Dawar N. Intrathecal nalbuphine as an adjuvant to subarachnoid block: What is the most effective dose? Anesth Essays Res 2011 Jul-Dec;5(2):171-5. [PubMed] [Free Full Text] doi: 10.4103/02591162.94759.

17. Kumaresan S, Raj AAM. Intrathecal nalbuphine as an adjuvant to spinal anaesthesia: What is most optimum dose? Int J Sci Stud 2017;5(1):5760 [Free Full Text] DOI: 10.17354/ ijss/2017/155

18. Jyothi B, Shaikh $S$ and Gowda S. A comparison of analgesic effect of different doses of intrathecal nalbuphine hydrochloride with bupivacaine and bupivacaine alone for lower abdominal and orthopedic surgeries. Indian J Pain 2014;28:1823. [Free Full Text]

19. Culebras X, Gaggero G, Zatloucal $J$, Kern C, Marti RA. Advantages of inrathecal nalbuphine, compared with intrathecal morphine, after caesarean delivery: an evaluation of postoperative analgesia and adverse effects. Anesth Analg 2000;91:601-5. [PubMed]

20. Rawal N, Nuutinen L, Lovering SL, Gobuty AH, Hargardine J, Lehmkuhl L, et al. Behavioral and histopathologic effects following intrathecal administration of butorphanol, sufentanil, and nalbuphine in sheep. Anesthesiology 1991;75:1025-34. [PubMed]

21. Parveen S, Prasad PK, Lakshmi BS. Evaluation of the effect of intrathecal nalbuphine as an adjuvant to spinal 


\section{nalbuphine vs clonidine as adjuvants to levobupivacaine}

$\begin{array}{lll}\text { bupivacaine for post-operative } & \text { hydrochloride with hyperbaric } \\ \text { analgesia in patients undergoing } & \text { bupivacaine } 0.5 \% \text { and hyperbaric } \\ \text { abdominal hysterectomy: A } & \text { bupivacaine } 0.5 \% \text { alone in patients } \\ \text { randomized, double blinded control } & \text { undergoing abdominal hysterectomy. } \\ \text { trial. Int J Sci Stud 2015;3(8):141-146 } & \text { Int J Res Med 2014:3(2);7-11 }\end{array}$

[Free Full Text]

22. Bisht S, Rashmi D. Comparison of intrathecal fentanyl and nalbuphine: A prospective randomized controlled study in patients undergoing total abdominal hysterectomy. Anaesth pain intensive care 2017;21(2):194-8 [Free Full Text]

23. Yoon JY, JeeYS, Hong JY. A comparison of analgesic effects and side effects of intrathecal morphine, nalbuphine and morphine - nalbuphine mixture for pain relief during a caesarean section. Korean J Anaesthesiol 2002;42:62733. [Free Full Text]

24. Patwa AA, Endigeri A, Upadhay MR. A comparison of intrathecal nalbuphine
25. Walker SM, Grafe M, Yaksh TL. Intrathecal clonidine in the neonatal rat: Dose-dependent analgesia and evaluation of spinal apoptosis and toxicity. Anesth Analg 2012;115: 45060. [PubMed] [Free Full Text]

26. Maheshwari N, Gautam S, Kapoor $R$, Prakash R, Jafa S, Gupta R. Comparative study of different doses of clonidine as an adjuvant with isobaric levobupivacaine for spinal anaesthesia in patients undergoing caesarean section. J Obstet Anaesth Crit Care 2019;9:9-13. [Free Full Text]

27. Chopra P, Talwar V. Low dose intrathecal clonidine and fentanyl added to hyperbaric bupivacaine

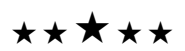

prolongs analgesia in gynecological surgery. J Anaesthesiol Clin Phramacol 2014;30:233-7. [PubMed] [Free Full Text]

28. Shah BB, Joshi SS, Shidhaye RV, Lakhe JN. Comparison of different doses of clonidine as an adjuvant to intrathecal bupivacaine for spinal anesthesia and postoperative analgesia in patients undergoing caesarean section. Anaesth Pain \& Intensive Care 2012;16(3):266-272. [Free Full Text]

29. Ingley P, Gadkari CP, Kalita N, Bhure AR. Intrathecal hyperbaric bupivacaine with two different doses of clonidine in lower limb orthopaedic surgery: A comparative study. J Med Sci Clin Res 2017;5(5):22147-22156. [Free Full Text] 